\title{
Quality of Life in Dementia
}

\author{
Gary Naglie
}

\begin{abstract}
There is a growing consensus that quality of life (QOL) is an important outcome for assessing the effectiveness of interventions for dementia, but there is no agreement about how to best measure it. Various approaches to QOL assessment have been employed to measure the QOL of persons with dementia, including patient self-report, caregiver proxy report and observational assessment by trained observers. Furthermore, several dementia-specific measures of QOL have been developed, and several generic measures of QOL have been used to assess QOL in dementia. However, to date, QOL has rarely been included as an outcome measure in clinical trials of pharmacotherapy for dementia. This manuscript reviews the current state of knowledge about QOL assessment in dementia.
\end{abstract}

RÉSUMÉ: Qualité de vie et démence. La qualité de vie (QDV) est de plus en plus reconnue comme étant importante dans l'évaluation de l'efficacité des interventions dans la démence. Cependant il n'existe pas de consensus sur la meilleure façon de la mesurer. Différentes approches ont été utilisées pour l'évaluer chez des patients déments, dont l'auto-évaluation, l'évaluation indirecte par le soignant et l'évaluation par des observateurs entraînés. De plus, plusieurs instruments de mesure de la QDV spécifiques de la démence ont été développés et plusieurs mesures génériques de la QDV ont été utilisées pour évaluer la QDV dans la démence. Cependant, la QDV a rarement été incluse comme critère d'évaluation dans les essais cliniques en pharmacothérapie de la démence jusqu'à maintenant. Ce manuscrit revoit les connaissances actuelles sur l'évaluation de la QDV dans la démence.

Can. J. Neurol. Sci. 2007; 34: Suppl. 1 - S57-61

Quality of life (QOL) measurement provides a subjective evaluation that captures the benefits and harms of a treatment and elements of health not detected by standard clinical outcomes. ${ }^{1}$ Quality of life has become increasingly recognized as an important outcome for assessing the effectiveness of dementia interventions. The International Working Group for the Harmonization of Dementia Guidelines has recommended that QOL be included as an outcome measure in dementia trials. ${ }^{2}$ Despite the growing consensus about the need to measure QOL in dementia trials, there is a lack of agreement about how to define and measure QOL. ${ }^{2-4}$ In keeping with the World Health Organization's definition of health, ${ }^{5}$ health-related QOL is generally considered to be a multidimensional construct that includes physical health, mental health, social function and general well-being. Numerous different quality of life measures have been developed, which can be categorized into diseasespecific or generic measures. ${ }^{6}$

\section{Disease-Specific Versus Generic QOL Measures}

Disease-specific QOL measures focus only on dimensions relevant to a specific disease, which tends to increase their responsiveness (i.e. their ability to identify changes that relate to the natural history of the disease or to treatment interventions). ${ }^{6}$ Generic measures allow for comparisons across different diseases or their treatments and can be helpful in health policy decisions. ${ }^{6}$ However, generic measures often exhibit less responsiveness than disease-specific measures, which may limit their usefulness in clinical trials. ${ }^{6}$ Generic measures can be classified as health profiles or utility measures. Health profiles, such as the Short Form-36 (SF-36) and the Sickness Impact Profile, classify an individual with respect to a broad spectrum of QOL domains. ${ }^{6}$ Utility measures provide a global measure of an individual's preference for a health state in a single number from 0 (death) to 1 (full health). ${ }^{6}$ Utility measures have the specific advantage of being readily incorporable into cost-effectiveness analyses that assess interventions in terms of their cost per

From the Division of General Internal Medicine, University Health Network; Geriatrics Program, Toronto Rehabilitation Institute; Division of Clinical DecisionMaking and Health Care, Toronto General Research Institute, University Health Network; Clinical Epidemiology and Health Care Research Program; Departments of Medicine and Health Policy, Management and Evaluation, University of Toronto, Toronto, Ontario, Canada.

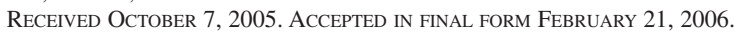
Reprint requests to: Gary Naglie, Toronto Rehabilitation Institute, 1008-550 University Avenue, Toronto, Ontario, M5G 2A2, Canada. 
quality-adjusted life year. ${ }^{6,7}$ Utilities can be directly elicited from individuals using standard techniques, or can be obtained from health indexes that incorporate both a health state classification system and a set of population-derived weights that yield a utility score. The three most commonly used health indexes are the Health Utilities Index (HUI), the European QOL scale (EQ-5D) and the Quality of Well-Being scale (QWB). ${ }^{8}$

\section{ApProaches to QOL Assessment in Dementia Patients}

Three approaches have been used for assessing QOL in dementia patients: 1) direct observation of behaviours and activities assumed to be related to QOL; 2) proxy reports by a family member or caregiver; and 3) self-reports by the individual with dementia. ${ }^{9,10}$ Until quite recently dementia patients were assumed not to be able to provide meaningful information about their QOL because of their cognitive impairments, leading to the proliferation of observational and proxy QOL measures. ${ }^{1,11}$ However, both these approaches exclude consideration of the patient's subjectively appraised experiences, which many believe to be an inherent feature of QOL. ${ }^{1,9,11}$ Central to the question of whether patients or caregivers should be asked to assess the patients' QOL is whether patients can reliably rate their own QOL and whether there is agreement between patients and caregivers regarding their ratings of patients' QOL.

In the advanced stages of dementia, patients are too cognitively impaired to rate their own QOL so we must rely on proxy reports or direct observation of QOL of patients. However, mounting evidence suggests that the majority of patients with mild-moderate dementia can meaningfully rate their own QOL. ${ }^{12-14}$ Mozley et $\mathrm{al}^{12}$ found that in a nursing home population, over $80 \%$ with MMSE scores $\geq 11$ could provide meaningful answers to a generic QOL questionnaire. Brod et $\mathrm{al}^{14}$ found that $96 \%$ of patients with MMSE scores $\geq 13$ were able to reliably and validly rate their own QOL using the Dementia QOL (DQOL) scale. Logsdon et $\mathrm{al}^{13}$ found that $88 \%$ of Alzheimer's patients were able to reliably and validly rate their QOL on the QOL-Alzheimer's Disease (QOL-AD) scale, and that all patients with MMSE scores $\geq 11$ were able to do so. Novella and colleagues $^{15,16}$ found that patient self-ratings could be reliably carried out in dementia patients with MMSE scores $\geq 15$ using the SF-36 and the Duke Health Profile using a facilitated interview process.

Several recent studies have compared the agreement between dementia patient and caregiver proxy ratings using diseasespecific and generic QOL instruments. ${ }^{13,17-21}$ These studies have shown that patients tend to rate their QOL significantly higher than their caregivers do and that there are significant differences between QOL ratings by different proxy sources. Various patient and caregiver factors can influence QOL ratings, thus contributing to discrepancies between raters. Such factors may include patient factors such as adaptation to their illness, as has been shown with other chronic illnesses, ${ }^{23}$ and loss of insight into their impairments, and caregiver factors such as caregiver burden and depression. ${ }^{19,22-25}$ These results suggest that although caregiver proxy ratings provide important QOL information from the perspective of persons without dementia, they do not accurately reflect the patients' subjective view of their own QOL. Therefore, whenever possible, studies should include both patient ratings (in those with mild-moderate dementia) and proxy ratings, since they provide distinct information reflecting different perspectives.

\section{Quality of Life Measures Used to Assess QOL IN Dementia Patients}

In the late 1980's, the Progressive Deterioration Scale (PDS) was developed as the first disease-specific measure to assess QOL in Alzheimer's disease. ${ }^{26}$ This 27 -item proxy measure was based primarily on daily activities, and current consensus is that the PDS is more a measure of function than a multidimensional measure of QOL. ${ }^{27}$ In the past ten years, several new QOL measures have been developed for dementia populations. Lawton $^{28}$ provided a theoretical model that has served as the basis for many dementia QOL measures. The model includes four dimensions: (1) behavioural competence (e.g. physical health, functional and cognitive abilities, and social behaviour); (2) psychological well being; (3) objective environment (e.g. social support, living situation); and (4) perceived overall QOL. Some of the new QOL measures have incorporated items from all four dimensions, while others have included items from only one or two. ${ }^{4}$

Two recent review articles and a recent book summarize disease-specific QOL measures that have been developed for dementia populations. ${ }^{3,4,29}$ These measures vary in many ways:

1. Content: some of the measures include a broad scope of QOL domains including function and cognition. Others have specifically excluded items about function and/or cognition with the rationale that these items are determinants rather than features of QOL, and others still have limited their focus to only one or two domains (e.g. activities, affect, behaviour). ${ }^{14,30-34}$

2. Respondent: some of the measures have been developed exclusively for patient or proxy (i.e. informal or formal caregiver) ratings, while some have been developed for either patient or proxy ratings.

3. Method of Administration: most patient and proxy rated measures are interviewer-administered, although some measures are self-administered, and direct observational measures require a trained assessor to observe specific behaviours and/or activities for a fixed period of time.

4. Target Population: many of the measures were developed mainly for use in patients with mild-moderate dementia, ${ }^{13,14,30,31,35,36}$ although others were developed primarily for use in severely demented or institutionalized patients, ${ }^{32,33}$ or for use across the spectrum of disease severity. ${ }^{37,38}$

Three disease-specific measures that have been used in several dementia studies and that have some data supporting their reliability and validity are the QOL-AD, the DQOL and the Alzheimer's Disease Related Quality of Life (ADRQL). ${ }^{4}$ The QOL-AD is a 13-item measure (physical health, energy, mood, living situation, memory, family, marriage, friends, chores, fun, money, self, and life as a whole) that was developed for either patient or proxy ratings. ${ }^{13,24,39,40}$ The DQOL is a 30 -item measure with five subscales (self-esteem, positive affect, negative affect, feelings of belonging and sense of aesthetics) and a single item to assess overall QOL that was developed initially exclusively for patient ratings, but that has subsequently also been used for proxy ratings. ${ }^{11,14,19,39}$ The ADRQL is a 47-item measure of 
positive and negative behaviours across five domains (social interactions, awareness of self, feelings and mood, enjoyment of activities and response to surroundings) that was developed for caregiver proxy ratings. ${ }^{37,39,41}$

Although disease-specific measures have received a lot of attention, many studies have also evaluated the use of generic health profile measures, including the SF-36, the Sickness Impact Profile, and the Nottingham and Duke Health Profiles, ${ }^{15,16,42}$ and utility measures, including the time-tradeoff, EQ-5D, QWB and HUI, ${ }^{17,21,40,43-47}$ for patient and/or proxy ratings in dementia populations. These studies provide evidence that various generic health profiles and the EQ-5D are reliable for patient ratings in patients with mild-moderate dementia, and that the EQ-5D, the QWB, the HUI and the time-tradeoff are reliable and valid for proxy ratings. ${ }^{17,40,44-47}$

\section{Quality of Life Measures in Dementia Clinical Trials}

Quality of life instruments selected for use in clinical trials must have established reliability and validity in the specific population being studied, as well as proven responsiveness to detect clinically relevant change. ${ }^{6}$ Although there are increasing data on the reliability and validity of several measures for assessing QOL in dementia, there are minimal data on their responsiveness, and there is no consensus on what change in QOL on any given measure constitutes a clinically significant change. ${ }^{4}$ In addition, little is known about the impact of various potential confounders (e.g. comorbidity, patient's living circumstance) on patient and proxy QOL ratings.

A recent systematic review of published randomized controlled trials (RCTs) of pharmacologic treatments for dementia, including tacrine (8 RCTs), donepezil (11 RCTs), rivastigmine (6 RCTs), galantamine (6 RCTs), metrifonate (9 RCTs), memantine (3 RCTs), selegiline (6 RCTs), estrogens (5 RCTs) and Gingko biloba (3 RCTs), showed that QOL was rarely included as an outcome measure. ${ }^{48}$ Four donepezil trials included the Blau QOL measure as a secondary outcome, ${ }^{49}$ assessing patient ratings in three trials, and patient and proxy ratings in one trial. $^{50-53}$ The Blau ${ }^{49}$ QOL is a generic measure covering 10 domains, with no data supporting its reliability or validity for patient or proxy ratings in dementia., ${ }^{3,27}$ The Blau QOL ratings in the donepezil trials exhibited marked variability within subjects and did not show any consistent treatment effects across the trials. ${ }^{52,53}$ One tacrine $\mathrm{RCT},{ }^{54}$ one donepezil RCT, ${ }^{55}$ two rivastigmine RCTs, ${ }^{56,57}$ and one galantamine $\mathrm{RCT}^{58}$ included the PDS as a secondary outcome measure. As mentioned earlier, most consider the PDS to be a measure of function rather than QOL. In fact, in three of the five RCTs in which it was used, it is referred to as a measure of daily activities. The PDS results were inconsistent across the trials. ${ }^{27}$

None of the newer dementia-specific QOL measures have been included in the published RCTs of pharmacologic treatments. However, a recent randomized trial of a cognitive stimulation therapy program included the QOL-AD as a secondary outcome measure and showed that the treatment group had a statistically significant improvement in the QOLAD. ${ }^{59}$ However, the effect size $(0.28)$ was small. ${ }^{60}$ Another recent clinical trial of the effects of a cognitive communication program plus a cholinesterase inhibitor in $\mathrm{AD}$ patients used the QOL-AD as a secondary outcome measure. ${ }^{61}$ This study showed no significant differences between the treatment and control groups.

\section{Quality of Life of Caregivers}

Although this review has focused primarily on the assessment of the QOL of patients with dementia, assessing the QOL of their caregivers is also important because it may be affected by antidementia treatments. ${ }^{62-66}$ Studies of caregiver outcomes have tended to focus more on constructs such as burden, affect and physical health than on QOL. ${ }^{67}$ Nevertheless, some studies have included QOL measures and have demonstrated that caregiving for patients with dementia has detrimental effects on caregiver QOL. ${ }^{64,68}$ The systematic review of RCTs of drug treatments for dementia ${ }^{48}$ documented only one trial that included a measure of caregiver QOL (the SF-36) as a secondary outcome measure, but the results for this outcome were not reported. ${ }^{69}$ If one of the goals of treatments for dementia is to improve caregiver outcomes, then it is imperative that caregiver QOL be included as an outcome measure.

\section{Conclusions}

Patient and caregiver QOL outcome measures should be included in studies of antidementia therapies. At this time no specific measures can be recommended. Disease-specific measures will likely be more responsive to treatment effects, while generic measures may be necessary to address policy issues such as cost-effectiveness. For patients with mildmoderate dementia, both patient and proxy rated QOL measures are encouraged, as they appear to provide different information. For patients with severe dementia, proxy and/or observational QOL measures are recommended. Future studies are needed to clarify the criteria for inclusion of patients for self-rating and for identifying the most appropriate proxy informants, to identify the characteristics of patients and proxies that influence their QOL ratings over time, and to determine which QOL measures are the most reliable, valid and responsive for specific dementia populations.

\section{DEClaRATION}

Dr. Naglie is supported by the Mary Trimmer Chair in Geriatric Medicine Research, University of Toronto. The Toronto Rehabilitation Institute receives funding under the Provincial Rehabilitation Research Program from the Ontario Ministry of Health and Long Term Care.

\section{REFERENCES}

1. Logsdon RG. Making the most of every day: quality of life in Alzheimer's disease. In: Harris PB, editor. The person with Alzheimer's disease: pathways to understanding the experience. Baltimore: Johns Hopkins Press; 2002: p. 75-87.

2. Mack JL, Whitehouse PJ. Quality of life in dementia: state of the art - report of the International Working Group for Harmonization of Dementia Drug Guidelines and the Alzheimer's Society satellite meeting. Alzheimer Dis Assoc Disord. 2001; 15:69-71.

3. Selai C, Trimble MR. Assessing quality of life in dementia. Aging \& Mental Health. 1999; 3:101-11.

4. Ready RE, Ott BR. Quality of life measures for dementia. Health Qual Life Outcomes. 2003; 1:11-9.

5. WHOQOL. Measuring quality of life. Geneva: The World Health Organization. 1997: 1-8. 
6. Guyatt GH, Feeny DH, Patrick DL. Measuring health-related quality of life. Ann Intern Med. 1993; 118:622-9.

7. Torrance GW. Measurement of health state utilities for economic appraisal. J Health Econ. 1986; 5:1-30.

8. Silberfeld M, Rueda S, Krahn M, Naglie G. Content validity for dementia of three generic preference based health related quality of life instruments. Qual Life Res. 2002; 11:71-9.

9. Whitehouse PJ. Alzheimer's disease: past, present, and future. Eur Arch Psychiatry Clin Neurosci. 1999; 249 Suppl 3:S43-5.

10. Weyerer S, Schaufele M. The assessment of quality of life in dementia. Int Psychogeriatr. 2003; 15:213-8.

11. Brod M, Stewart AL, Sands L. Conceptualization of quality of life in dementia. J Mental Health Aging. 1999; 5:7-19.

12. Mozley CG, Huxley P, Sutcliffe C, Bagley H, Burns A, Challis D, et al. 'Not knowing where I am doesn't mean I don't know what I like': cognitive impairment and quality of life responses in elderly people. Int J Geriatr Psychiatry. 1999; 14:776-83.

13. Logsdon RG, Gibbons LE, McCurry S, Teri L. Assessing quality of life in older adults with cognitive impairment. Psychosom Med. 2002; 64:510-9.

14. Brod M, Stewart AL, Sands L, Walton P. Conceptualization and measurement of quality of life in dementia: the dementia quality of life instrument (DQoL). Gerontologist. 1999; 39:25-35.

15. Novella J, Ankri J, Morrone I, Guillemin F, Jolly D, Jochum C, et al. Evaluation of the quality of life in dementia with a generic quality of life questionnaire: the Duke Health Profile. Dement Geriatr Cogn Disord. 2001; 12:158-66.

16. Novella JL, Jochum C, Ankri J, Morrone I, Jolly D, Blanchard F. Measuring general health status in dementia: practical and methodological issues in using the SF-36. Aging-Clinical \& Experimental Research. 2001; 13:362-9.

17. Naglie G, Tomlinson G, Tansey C, Irvine J, Ritvo P, Black S, et al. Utility-based quality of life measures in Alzheimer's disease. Qual Life Res. 2006;15:631-43.

18. Ready RE, Ott BR, Grace J. Patient versus informant perspectives of quality of life in mild cognitive impairment and Alzheimer's disease. Int J Geriatr Psychiatry. 2004; 19:256-65.

19. Sands LP, Ferreira P, Stewart AL, Brod M, Yaffe K. What explains differences between dementia patients' and their caregivers' ratings of patients' quality of life? Am J Geriatr Psychiatry. 2004; 12:272-80.

20. Novella JL, Jochum C, Jolly D, Morrone I, Ankri J, Bureau F, et al. Agreement between patients' and proxies' reports of quality of life in Alzheimer's disease. Qual Life Res. 2001; 10:443-52.

21. Coucill W, Bryan S, Bentham P, Buckley A, Laight A. EQ-5D in patients with dementia an investigation of inter-rater agreement. Med Care. 2001; 39:760-71.

22. Karlawish JH, Casarett D, Klocinski J, Clark CM. The relationship between caregivers' global ratings of Alzheimer's disease patients' quality of life, disease severity, and the caregiving experience. J Am Geriatr Soc. 2001; 49:1066-70.

23. Spranger MA, Aaronson NK. The role of health care providers and significant others in evaluating the quality of life of patients with chronic disease: a review. J Clin Epidemiol. 1992; 45:743-60.

24. Logsdon RG, Gibbons LE, McCurry SM, Teri L. Quality of life in Alzheimer's disease: patient and caregiver reports. J Mental Health Aging. 1999; 5:21-32.

25. Boyer F, Novella J-L, Morrone I, Jolly D, Blanchard F. Agreement between dementia patient report and proxy reports using the Nottingham Health Profile. Int J Geriatr Psychiatry. 2004; 19:1026-34

26. DeJong R, Osterlund OW, Roy GW. Measurement of quality-of-life changes in patients with Alzheimer's disease. Clin Ther. 1989; 11:545-54.

27. Demers L, Oremus M, Perrault A, Champoux N, Wolfson C. Review of outcome measurement instruments in Alzheimer's disease drug trials: psychometric properties of functional and quality of life scales. J Geriatr Psychiatry Neurol. 2000; 13:170-80.

28. Lawton MP. Quality of life in Alzheimer disease. Alzheimer Dis Assoc Disord. 1994; 8 Suppl 3:S138-50.

29. Assessing quality of life in Alzheimer's disease. Albert SM, Logsdon RG, editors. New York: Springer Publishing Company, Inc; 2000.
30. Ready R, Ott B, Grace J, Fernandez I. The Cornell-Brown scale for quality of life in dementia. Alzheimer Dis Assoc Disord. 2002; 16:109-15.

31. Burgener S, Twigg P. Relationships among caregiver factors and quality of life in care recipients with irreversible dementia. Alzheimer Dis Assoc Disord. 2002; 16:88-102.

32. Weiner M, Martin-Cook K, Svetlik D, Saine K, Foster B, Fontaine CS. The quality of life in late-stage dementia (QUAL-ID) Scale. J Amer Med Dir Assoc. 2000; 1:114-6.

33. Fossey J, Lee L, Ballard C. Dementia care mapping as a research tool for measuring quality of life in care setting: psychometric properties. Int J Geriatr Psychiatry. 2002; 17:1064-70.

34. Albert SM, Del Castillo-Castaneda C, Sano M, Jacobs DM, Marder $\mathrm{K}$, Bell K, et al. Quality of life in patients with Alzheimer's disease as reported by patient proxies. J Am Geriatr Soc. 1996; 44:1342-7.

35. Coon D, Mace N, Weaverdyck S. Resident behaviour/life quality inventory. In: Coon D, Mace N, editors. Quality of life in longterm care. New York: Haworth Press; 1996.

36. Selai CE, Trimble MR, Harvey RJ. Assessing quality of life in dementia: preliminary psychometric testing of the Quality of Life Assessment Schedule (QOLAS). Neuropsychological Rehabilitation. 2001; 11:219-43.

37. Rabins PV, Kasper JD, Kleinman L, Black BS, Patrick DL. Concepts and methods in the development of the ADRQL: An instrument for assessing health-related quality of life in persons with Alzheimer's disease. Journal of Mental Health and Aging. 1999; 5:33-48.

38. Albert SM, Marks J, Barrett V, Gurland B. Home health care and quality of life of patients with Alzheimer's disease. Am J Prev Med. 1997; 13:63-8.

39. Edelman P, Fulton BR, Kuhn D. Comparison of dementia-specific quality of life measures in adult day centres. Home Health Care Services Quarterly. 2004; 23:25-42.

40. Thorgrimsen L, Selwood A, Spector A, Royan L, de Madariaga Lopez M, Woods RT, et al. Whose quality of life is it anyway? The validity and reliability of the quality of life-Alzheimer's disease (QOL-AD) scale. Alzheimer Dis Assoc Disord. 2003; 17:201-8.

41. Gonzalez-Salvador T, Lyketsos CG, Baker A, Hovanec L, Roques C, Brandt J, et al. Quality of life in dementia patients in long-term care. Int J Geriatr Psychiatry. 2000; 15:181-9.

42. Bureau-Chalot F, Novella JL, Jolly D, Ankri J, Guillemin F, Blanchard F. Feasibility, acceptability and internal consistency reliability of the Nottingham Health Profile in dementia patients. Gerontology. 2002; 48:220-5.

43. Mador J, Clark M, Crotty M, Hecker J. Utility-weighted measures of quality of life in Alzheimer disease. Alzheimer Dis Assoc Disord. $2002 ; 16: 202-3$

44. Sano M, Albert SM, Tractenberg R, Schittini M. Developing utilities: quantifying quality of life for stages in Alzheimer's disease as measured by the clinical dementia rating. In: Albert SM, Logsdon $\mathrm{R}$, editors. Assessing quality of life in Alzheimer's disease. New York: Springer Publishing; 2000: p. 81-92.

45. Kerner DN, Patterson TL, Grant I, Kaplan RM. Validity of the quality of well-being scale for patients with Alzheimer's disease. J Aging Health. 1998; 10:44-61.

46. Neumann PJ, Kuntz KM, Leon J, Araki SS, Hermann RC, Hsu MA, et al. Health utilities in Alzheimer's disease: a cross-sectional study of patients and caregivers. Med Care. 1999; 37:27-32.

47. Ankri J, Beaufils B, Novella J-L, Morrone I, Guillemin F, Jolly D, et al. Use of the EQ-5D among patients suffering from dementia. J Clin Epidemiol. 2003; 56:1055-63.

48. Santaguida P, Raina P, Booker L, Patterson C, Baldassarre F, Cowan $\mathrm{D}$, et al. Pharmacological treatment of dementia: evidence report/technology assessment no. 97 (Prepared by McMaster University Evidence-based Practice Center under contract no. 290-02-0020). AHRQ Publication No. 04-E018-2. Rockville, MD: Agency for Healthcare Research and Quality. April 2004.

49. Blau TH. Quality of life, social indicators, and criteria of change. Professional Psychology. 1977:464-73. 
50. Rogers SL, Doody RS, Mohs RC, Friedhoff LT, the Donepezil Study Group. Donepezil improves cognition and global function in Alzheimer disease. Arch Intern Med. 1998; 158:1021-31.

51. Burns A, Rossor M, Hecker J, Gauthier S, Petit H, Moller HJ, et al. The effects of donepezil in Alzheimer's disease - results from a multinational trial. Dement Geriatr Cogn Disord. 1999; 10:23744.

52. Rogers SL, Friedhoff LT. The efficacy and safety of donepezil in patients with Alzheimer's disease: results of a US Multicentre, randomized, double-blind, placebo-controlled trial. The Donepezil Study Group. Dementia. 1996; 7:293-303.

53. Rogers SL, Farlow MR, Doody RS, Mohs R, Friedhoff LT. A 24week, double-blind, placebo-controlled trial of donepezil in patients with Alzheimer's disease. Donepezil Study Group. Neurology. 1998; 50:136-45.

54. Knapp MJ, Knopman DS, Solomon PR, Pendlebury WW, Davis CS, Gracon SI. A 30-week randomized controlled trial of high-dose tacrine in patients with Alzheimer's disease. The Tacrine Study Group. JAMA. 1994; 271:985-91.

55. Winblad B, Engedal K, Soininen H, Verhey F, Waldemar G, Wimo A, et al. A 1-year, randomized, placebo-controlled study of donepezil in patients with mild to moderate AD. Neurology. 2001; 57:489-95.

56. Corey-Bloom J, Anand R, Veach J. A randomized trial evaluating the efficacy and safety of ENA 713 (rivastigmine tartrate), a new acetylcholinesterase inhibitor, in patients with mild to moderately severe Alzheimer's disease. Int J Geriatr Psychopharm. 1998; $1: 55-65$

57. Rosler M, Anand R, Cicin-Sain A, Gauthier S, Agid Y, Dal-Bianco P, et al. Efficacy and safety of rivastigmine in patients with Alzheimer's disease: international randomized controlled trial. BMJ. 1999; 318:633-8.

58. Wilkinson D, Murray J. Galantamine: a randomized, double-blind, dose comparison in patients with Alzheimer's disease. Int $\mathbf{J}$ Geriatr Psychiatry. 2001; 16:852-7.
59. Spector A, Thorgrimsen L, Woods B, Royan L, Davies S, Butterworth M, et al. Efficacy of an evidence-based cognitive stimulation therapy programme for people with dementia. Br J Psychiatry. 2003; 183:248-54.

60. Cohen J. Statistical power analysis for the behavioural sciences. London: Academic Press; 1969.

61. Chapman SB, Weiner MF, Rackley A, Hynan LS, Zientz J. Effects of cognitive-communication stimulation for Alzheimer's disease patients treated with donepezil. J Speech Lang Hear Res. 2004; 47:1149-63.

62. Feldman H, Gauthier S, Hecker J, Vellas B, Emir B, Mastey V, et al. Efficacy of donepezil on maintenance of activities of daily living in patients with moderate-to-severe Alzheimer's disease and the effect on caregiving burden. J Am Geriatr Soc. 2003; 51:737-44.

63. Bullock R. The needs of the caregiver in the long-term treatment of Alzheimer disease. Alzheimer Dis Assoc Disord. 2004; 18: S17-23.

64. Markowitz JS, Guterman EM, Sadik K, Papadopoulos G. Healthrelated quality of life for caregivers of patients with Alzheimer disease. Alzheimer Dis Assoc Disord. 2003; 17:209-14.

65. Busschbach JJ, Brouwer WB, van der Donk A, Passchier J, Rutten FF. An outline for a cost-effectiveness analysis of a drug for patients with Alzheimer's disease. Pharmacoeconomics. 1998; 13:21-34.

66. Fillit HM, Gutterman EM, Brooks RL. Impact of donepezil on caregiving burden for patients with Alzheimer's disease. Int Psychogeriatr. 2000; 12:389-401.

67. Schulz R, O'Brien A, Czaja S, Ory MG, Norris R, Martire LM, et al. Dementia caregiver intervention research: in search of clinical significance. Gerontologist. 2002; 42:589-602.

68. Walker MD, Salek SS, Bayer AJ. A review of quality of life in Alzheimer's disease. Issues in assessing disease impact. Pharmacoeconomics. 1998; 14: (pt1) 499-530.

69. Feldman H, Gauthier S, Hecker J, Vellas B, Subbiah P, Whalen E, et al. A 24-week, randomized, double-blind study of donepezil in moderate to severe Alzheimer's disease. Neurology. 2001; 57:613-20. 